\title{
Altered functional connectivity of the default mode network by glucose loading in young, healthy participants
}

Kenji Ishibashi ${ }^{*} \mathbb{B}$, Keita Sakurai ${ }^{2}$, Keigo Shimoji², Aya M. Tokumaru² and Kenji Ishii ${ }^{1}$

\begin{abstract}
Background: The functional connectivity of the default mode network (DMN) decreases in patients with Alzheimer's disease (AD) as well as in patients with type 2 diabetes mellitus (T2DM). Altered functional connectivity of the DMN is associated with cognitive impairment. T2DM is a known cause of cognitive dysfunction and dementia in the elderly, and studies have established that T2DM is a risk factor for AD. In addition, recent studies with positron emission tomography demonstrated that increased plasma glucose levels decrease neuronal activity, especially in the precuneus/posterior cingulate cortex (PC/PCC), which is the functional core of the DMN. These findings prompt the question of how increased plasma glucose levels decrease neuronal activity in the PC/PCC. Given the association among $D M N, A D$, and T2DM, we hypothesized that increased plasma glucose levels decrease the DMN functional connectivity, thus possibly reducing PC/PCC neuronal activity. We conducted this study to test this hypothesis.
\end{abstract}

Results: Twelve young, healthy participants without T2DM and insulin resistance were enrolled in this study. Each participant underwent resting-state functional magnetic resonance imaging in both fasting and glucose loading conditions to evaluate the DMN functional connectivity. The results showed that the DMN functional connectivity in the PC/PCC was significantly lower in the glucose loading condition than in the fasting condition $(P=0.014)$.

Conclusions: Together with previous findings, the present results suggest that decreased functional connectivity of the DMN is possibly responsible for reduced PC/PCC neuronal activity in healthy individuals with increased plasma glucose levels.

Keywords: Resting-state functional MRI, Default mode network, Glucose, Precuneus, Posterior cingulate

\section{Background}

The default mode network (DMN), one of the restingstate brain networks, is characterized by hyperactivity when the brain is not engaged in specific behavioral tasks and low activity when the brain is focused on the external environment [1]. While performing various active tasks including novel, non-self-referential, and goal-directed tasks, the functional connectivity of the DMN consistently decreases $[2,3]$. Although the mechanisms are not completely known, the DMN plays an important role in regulating complex cognition and behavior [4-6]

\footnotetext{
*Correspondence: ishibashi@pet.tmig.or.jp

1 Research Team for Neuroimaging, Tokyo Metropolitan Institute of Gerontology, 35-2 Sakae-cho, Itabashi-ku, Tokyo 173-0015, Japan

Full list of author information is available at the end of the article
}

Its functional connectivity is impaired in patients with Alzheimer's disease (AD) [7], and impairment worsens with disease progression [8]. Furthermore, altered functional connectivity of the DMN is associated with cognitive decline $[9,10]$. Interestingly, the DMN functional connectivity can also decrease in patients with type 2 diabetes mellitus (T2DM) [11-13]. Although T2DM, characterized by insulin resistance and increased plasma glucose levels, is intuitively far from AD pathophysiology, T2DM is reportedly associated with cognitive decline and is a risk factor for AD [14]. Although it is unclear why $\mathrm{T} 2 \mathrm{DM}$ is a risk factor for $\mathrm{AD}$, the shared vulnerability of the DMN in the two diseases may reveal a functional association between them. 
The functional connectivity in resting-state brain networks is measured by detecting spontaneous fluctuations in the blood-oxygen-level-dependent (BOLD) signals with functional magnetic resonance imaging (fMRI) [15]. Positive BOLD signals are presumably caused by altered cerebral blood flow, an index of neuronal activity [16]. Therefore, the functional connectivity in resting-state brain networks may be associated with neuronal activity [17]. As one of the most fundamental resting-state brain networks, the DMN comprises a set of interconnected brain regions, such as the precuneus/posterior cingulate cortex (PC/PCC), medial prefrontal cortex (MPFC), and lateral parietotemporal cortex (LPTC), with the PC/ PCC being the functional core of the DMN $[4,5]$. In AD patients, functional connectivity of the DMN is impaired $[7,8]$; glucose metabolism, another index of neuronal activity, is compromised primarily in the PC/PCC $[18$, 19]. Therefore, in AD patients, decreased functional connectivity of the DMN is possibly associated with reduced neuronal activity in the PC/PCC.

Resting-state glucose metabolism, measured by fluorine-18-labeled fluorodeoxyglucose $\left({ }^{18} \mathrm{~F}\right.$-FDG) PET, is physiologically associated with neuronal activity [20]. Interestingly, recent studies using ${ }^{18} \mathrm{~F}$-FDG PET showed that neuronal activity in the $\mathrm{PC} / \mathrm{PCC}$ significantly decreases with increased plasma glucose levels in young, healthy individuals [21] as well as in cognitively normal elderly individuals [22-24]. The reduction in PC/PCC neuronal activity has been shown to occur in cognitively normal individuals with plasma glucose levels between 100 and $110 \mathrm{mg} / \mathrm{dL}$ [25] as well as in individuals developing insulin resistance [26]. Reversibly increasing and decreasing plasma glucose levels decease and increase PC/PCC neuronal activity, respectively, in cognitively normal individuals with T2DM [27]. Cerebral blood flow can also decrease in the PC/PCC as plasma glucose levels increase [21]. More recently, we measured net glucose metabolism using ${ }^{18}$ F-FDG PET with arterial blood sampling in young, healthy individuals under fasting and glucose loading conditions, and confirmed that glucose loading can reduce glucose metabolism (i.e., neuronal activity), especially in the PC/PCC [28]. These findings prompt the question of how increased plasma glucose levels decrease neuronal activity, especially in the $\mathrm{PC} /$ PCC.

Given the association among the DMN, AD, and T2DM, decreased functional connectivity of the DMN may be responsible for reduced neuronal activity in the PC/PCC. Therefore, we hypothesized that increased plasma glucose levels decrease the functional connectivity of the DMN even in healthy individuals without T2DM and insulin resistance, possibly thus reducing PC/ PCC neuronal activity. To test this hypothesis, we used resting-state fMRI to compare the functional connectivity of the DMN in young, healthy participants under fasting and glucose loading conditions.

\section{Methods \\ Research participants}

The study was conducted in accordance with the tenets of the Declaration of Helsinki, and was approved by the Ethics Committee of the Tokyo Metropolitan Institute of Gerontology. After a detailed explanation of the study, each participant provided written informed consent. The study was composed of 12 young, healthy participants [six males and six females, age: $30.3 \pm 4.6$ years (mean \pm SD), range: $24-36$ years]. None of the participants had a history of T2DM, and all were certified to be healthy based on the results of physical and neurological examinations, medical interviews with a neurologist, and MRI findings.

\section{Study protocol}

Each participant visited the Tokyo Metropolitan Institute of Gerontology twice to undergo a resting-state fMRI under each of two different conditions: fasting and glucose loading. The order in which the participants presented for imaging under the two conditions was randomized. Half of the male and half of the female participants underwent the first and second resting-state fMRI sessions under fasting and glucose loading conditions, respectively. The other participants underwent the two resting-state fMRI sessions in the reverse order. The time interval between the two visits was less than 30 days. In the fasting condition, each participant visited the institute to undergo a resting-state fMRI after fasting overnight for at least $8 \mathrm{~h}$. In the glucose loading condition, each participant visited the institute without having been under any dietary restriction, and was administered $75 \mathrm{~g}$ of glucose orally (TRELAN-G75; AY Pharma, Tokyo, Japan) approximately $30 \mathrm{~min}$ prior to the resting-state fMRI.

The plasma glucose levels, plasma insulin levels, and HbA1c values were measured after each resting-state fMRI, using ultraviolet absorption spectrophotometry, chemiluminescent enzyme immunoassay, and latex agglutination, respectively (SRL, Tokyo, Japan). The homeostasis model assessment of insulin resistance (HOMA-IR) was calculated as an index of insulin resistance using the following formula: HOMA-IR = (fasting glucose $(\mathrm{mmol} / \mathrm{L}) \times$ fasting insulin $(\mu \mathrm{U} / \mathrm{mL})) / 22.5$.

\section{Magnetic resonance data acquisition}

Imaging data were acquired on a Discovery MR 750w 3.0-T scanner (GE Healthcare, Milwaukee, WI) at the Tokyo Metropolitan Institute of Gerontology. 
High-resolution anatomical data were collected using an SPGR sequence (repetition time $=7.648 \mathrm{~ms}$, echo time $=3.092 \mathrm{~ms}$, flip angle $=11^{\circ}$, matrix size $=196 \times 256 \times 256$, voxel size $=1.2 \quad \mathrm{~mm} \times 1.0547$ $\mathrm{mm} \times 1.0547 \mathrm{~mm})$. Whole-brain resting-state $\mathrm{fMRI}$ data were collected using an echo planar imaging (EPI) sequence (repetition time $=2500 \mathrm{~ms}$, echo time $=30 \mathrm{~ms}$, flip angle $=73^{\circ}$, slice thickness $=4 \mathrm{~mm}$, matrix size $=64 \times 64 \times 41, \mathrm{FOV}=192 \mathrm{~mm} \times 192 \mathrm{~mm})$. The participants were instructed to rest quietly with their eyes open and to avoid specific thoughts during the restingstate fMRI sessions. Subsequently, the procedure was manually reviewed to verify that all participants followed the instructions correctly.

\section{Resting-state fMRI data processing and independent component analysis (ICA)}

The resting-state fMRI data were processed using the FMRIB Software Library version 5.0.9 (FSL; Oxford, UK) [29-31]. The first 10 volumes (images) were discarded to avoid transient signal changes before magnetization reached a steady state and to allow the participants to become accustomed to the fMRI scanning noise [32]. Then, the following 120 volumes, equivalent to $5 \mathrm{~min}$ of resting-state fMRI, were realigned to compensate for motion. Each motion-corrected EPI image was registered to the corresponding high-resolution SPGR image, and transformed into the Montreal Neurological Institute space using a 12-parameter affine transformation and a nonlinear transformation. The data were skull-stripped and spatially smoothed using a 5-mm full width at a half maximum Gaussian kernel, and a high-pass temporal filter of $100 \mathrm{~s}$ was applied.

Probabilistic independent component analysis (ICA) was then performed to identify the functional anatomy of the DMN, and to create a DMN mask for the subsequent seed-based analysis. A multi-session temporal concatenation approach was applied to all echo planar imaging sequence images. This approach allowed for a single $2 \mathrm{D}$ ICA run on the concatenated data matrix to be obtained by stacking the $2 \mathrm{D}$ data matrices of every data set on top of each other (https://fsl.fmrib.ox.ac.uk/fsl/fslwiki/ MELODIC). FSL Melodic was used to carry out inference on the estimated maps using a mixture model and an alternative hypothesis testing approach. A threshold level of 0.5 was applied to each mixture model probability map. This threshold level implies that a voxel "survives" thresholding as soon as the probability of being in the "active" class exceeds that of being in the "background noise" class, and assumes that the probability of falsenegative and false-positive findings is equal [33, 34]. Of the 25 IC maps created by FSL Melodic, we identified one IC map representing the default mode network (Fig. 1).

\section{Seed-based analysis and statistical analysis}

The thresholded IC map, shown in Fig. 1, included the representative components of the DMN: the PC/PCC, the MPFC, and the LPTC. These components were

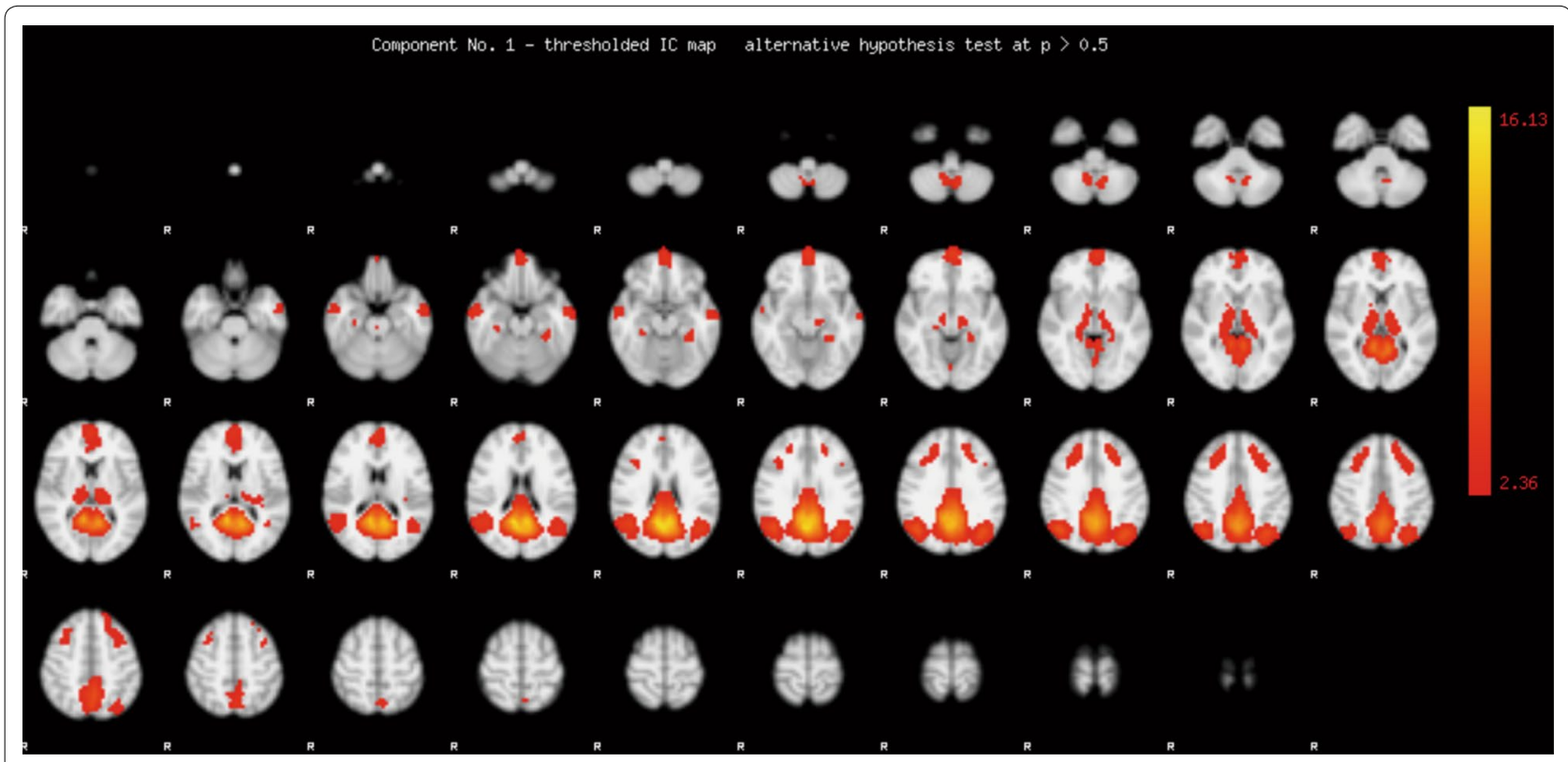

Fig. 1 Independent component map representing the default mode network. Independent component analysis was performed on all echo planar imaging sequence images using a multi-session temporal concatenation approach implemented in FSL Melodic. The mixture model probability map was transformed into a $Z$ map. The red-yellow scale represents the magnitude of $Z$ values ranging from 2.36 to 16.13 
extracted from the IC map and used as a mask for the DMN (Fig. 2a). Using the mask for the DMN as a seed, the mean time series across all voxels within the seed was extracted from each EPI image. A first-level analysis was performed for each 4D EPI image. The extracted mean time series was set as a covariate. We added the following variables as nuisance regressors: mean signals of cerebrospinal fluid and white matter, and metrics of motionrelated artifact created by FSL Mcflirt and Motion Outliers [35, 36]. A one-sample $t$ test was then performed as a higher-level analysis for each of the two conditions to assess the within-group functional connectivity of the DMN, using FSL Feat (https://fsl.fmrib.ox.ac.uk/fsl/fslwi ki/FEAT). $Z$ statistic images were thresholded using clusters determined by $Z>2.3$ and a corrected cluster significance of $P<0.05$.

A between-group analysis was then performed to test the hypothesis that increased plasma glucose levels decrease the functional connectivity of the DMN. The central area of the PC/PCC was extracted from the IC map as shown in Fig. 1 and used as a mask for the PC/PCC (Fig. 2b). The mask was moved on each $Z$ map that was created in the first-level analysis, as described above. The individual mean $Z$ value within the mask was calculated, and used as the index of the magnitude of the functional connectivity of the DMN in the PC/ PCC. To assess the effects of glucose loading on the functional connectivity of the DMN in the PC/PCC, $Z$ values were compared between the fasting and glucose loading conditions using a one-tailed Wilcoxon signedrank test. The null hypothesis was that the functional connectivity of the DMN in the glucose loading condition was not lower than in the fasting condition. Additionally, in order to assess whether any factors affected the changes in the functional connectivity of the DMN after glucose loading, a multiple regression analysis was employed using the difference in $Z$ values between the two conditions as a dependent factor and the order of conditions, gender, HOMA-IR, fasting plasma glucose and insulin levels, and HbA1c values as independent factors. Statistical significance was set at $P<0.05$. All statistical analyses were conducted using SPSS Statistics version 22 (IBM, Armonk, NY).

\section{Results}

The demographic characteristics are presented in Table 1. After glucose loading, plasma glucose and insulin levels significantly increased (glucose: $Z=2.158$, $P=0.031$, insulin: $Z=3.061, P=0.002$, two-tailed Wilcoxon signed-rank test). All participants were confirmed to be free of T2DM and insulin resistance on the basis of HOMA-IR, fasting plasma glucose levels, and HbA1c values [37].

The results of the one-sample $t$ tests $(Z>2.3$, clustercorrected $P<0.05)$ are shown in Fig. 3. The representative components of the DMN (PC/PCC, MPFC, and LPTC) were detected in the two conditions. The results of the between-group analysis of the magnitude of the $\mathrm{DMN}$ functional connectivity in the PC/PCC are shown in Fig. 4. The functional connectivity of the DMN in the PC/PCC was significantly lower in the glucose loading condition than in the fasting condition $(Z=2.197$, $P=0.014$, one-tailed Wilcoxon signed-rank test).

Multiple regression analyses revealed no significant factors that may have affected the changes in functional connectivity between the two conditions $\left[R^{2}=0.176\right.$, $F(6,5)=0.178, P=0.971$, order of conditions: $t=0.380$, $P=0.719$, gender: $t=0.362, P=0.732$, HOMA-IR: $t=0.041, P=0.969$, fasting plasma glucose: $t=0.310$, $P=0.769$, fasting plasma insulin: $t=0.038, P=0.971$, HbA1c: $t=0.721, P=0.503]$.

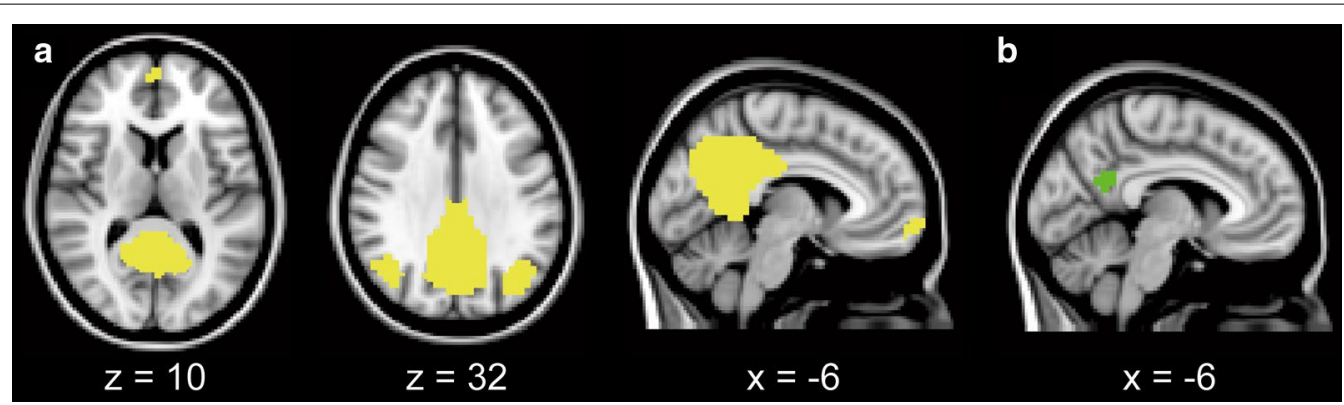

Fig. 2 Masks for the representative components of the DMN (a) and PC/PCC (b) in the Montreal Neurological Institute space. The representative components of the DMN were extracted from the IC map shown in Fig. 1, and used as a mask for the DMN (a yellow). The voxels with the highest statistical values were extracted from the IC map shown in Fig. 1, and used as a mask for the PC/PCC (b green). The mask volume for the PC/PCC was $2360 \mathrm{~mm}^{3}$. DMN default mode network, IC independent component, PC/PCC precuneus/posterior cingulate cortex 
Table 1 Demographic and clinical characteristics

\begin{tabular}{|c|c|c|c|c|c|c|c|c|}
\hline \multirow[t]{2}{*}{ Subject } & \multirow[t]{2}{*}{ Age } & \multirow[t]{2}{*}{ Sex } & \multirow[t]{2}{*}{ HbA1c (\%) } & \multicolumn{3}{|l|}{ Fasting } & \multicolumn{2}{|l|}{ Glucose loading } \\
\hline & & & & $\begin{array}{l}\text { Glucose (mg/ } \\
\mathrm{dL})\end{array}$ & $\begin{array}{l}\text { Insulin }(\mu \mathrm{U} / \\
\mathrm{mL})\end{array}$ & HOMA-IR & Glucose (mg/dL) & Insulin $(\mu \mathrm{U} / \mathrm{mL})$ \\
\hline 1 & 34 & M & 5.2 & 94 & 2.7 & 0.62 & 126 & 37.8 \\
\hline 2 & 34 & M & 5.8 & 80 & 6.5 & 1.28 & 164 & 32.2 \\
\hline 3 & 27 & M & 5.5 & 84 & 0.8 & 0.16 & 85 & 4.8 \\
\hline 4 & 32 & $\mathrm{~F}$ & 4.7 & 90 & 4.4 & 0.98 & 96 & 18.1 \\
\hline 5 & 30 & $\mathrm{~F}$ & 5.1 & 82 & 3.4 & 0.69 & 100 & 27.8 \\
\hline 6 & 36 & $\mathrm{~F}$ & 5.2 & 87 & 2.7 & 0.58 & 117 & 33.4 \\
\hline 7 & 23 & M & 5.4 & 91 & 2.4 & 0.53 & 115 & 18.7 \\
\hline 8 & 26 & $F$ & 4.9 & 94 & 4.2 & 0.98 & 84 & 8.0 \\
\hline 9 & 37 & $\mathrm{~F}$ & 5.1 & 87 & 1.8 & 0.40 & 186 & 87.4 \\
\hline 10 & 32 & M & 5.1 & 90 & 3.4 & 0.75 & 123 & 29.1 \\
\hline 11 & 24 & M & 4.9 & 89 & 1.9 & 0.42 & 83 & 29.0 \\
\hline 12 & 29 & $\mathrm{~F}$ & 5.3 & 82 & 4.3 & 0.88 & 75 & 26.5 \\
\hline Mean & & & 5.2 & 87.5 & 3.2 & 0.69 & 112.8 & 29.4 \\
\hline
\end{tabular}

HOMA-IR homeostasis model assessment of insulin resistance

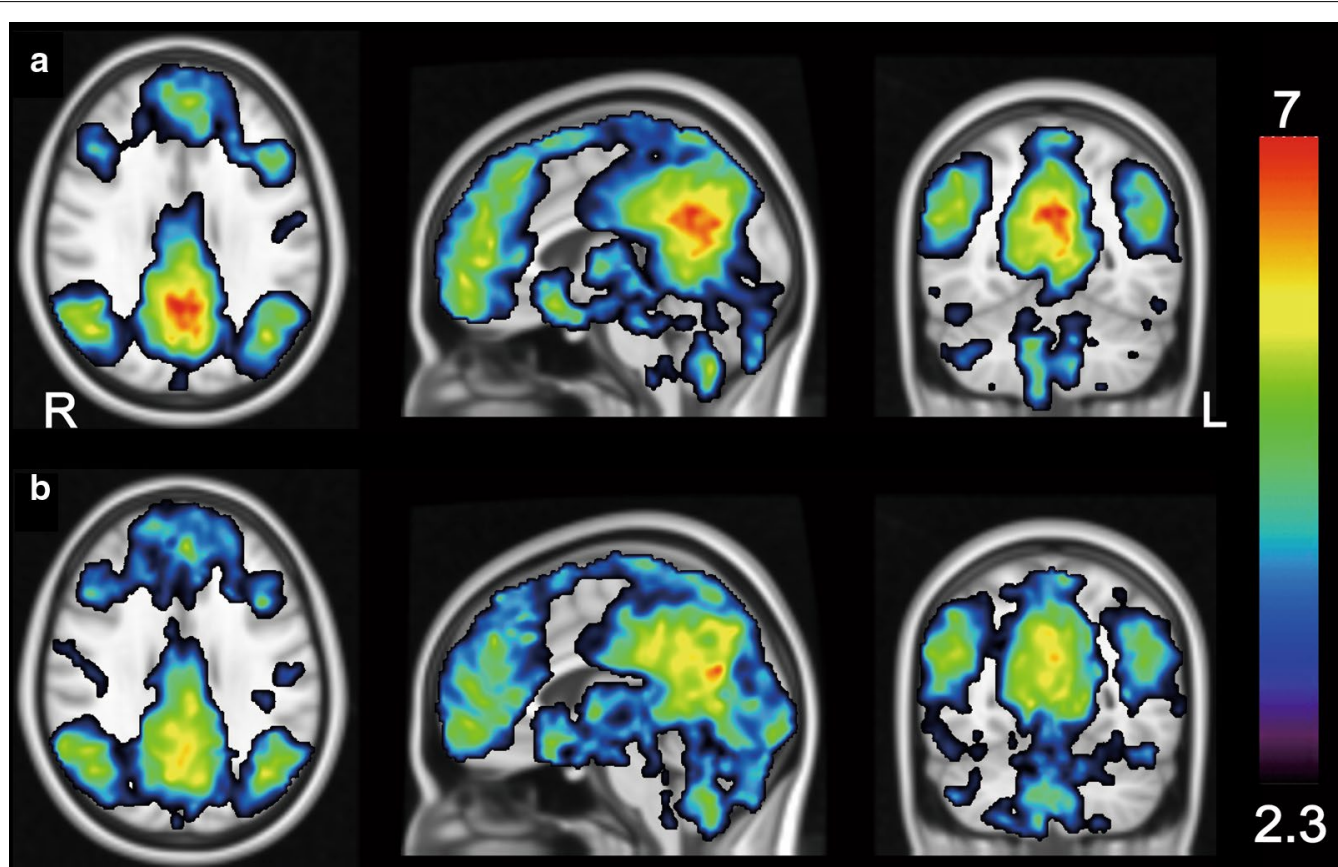

Fig. 3 Within-group functional connectivity of the DMN using a one-sample $t$ test. A seed was placed on the representative components of the DMN as shown in Fig. 2a. The magnitude of the DMN functional connectivity is displayed in the fasting condition (a) and glucose loading condition (b). The threshold was set at $Z>2.3$ and cluster-corrected $P<0.05$. The rainbow scale represents the magnitude of the $Z$ values. $R$ right, $L$ left, $D M N$ default mode network

\section{Discussion}

The primary objective of this study was to investigate the effects of glucose loading on the functional connectivity of the DMN in young, healthy subjects free of T2DM and insulin resistance, using resting-state fMRI. The functional connectivity of the DMN is known to decrease in patients with T2DM, characterized by insulin resistance and increased plasma glucose levels [11-13]. To the best of our knowledge, this is the first study showing that after glucose loading, the functional connectivity of 


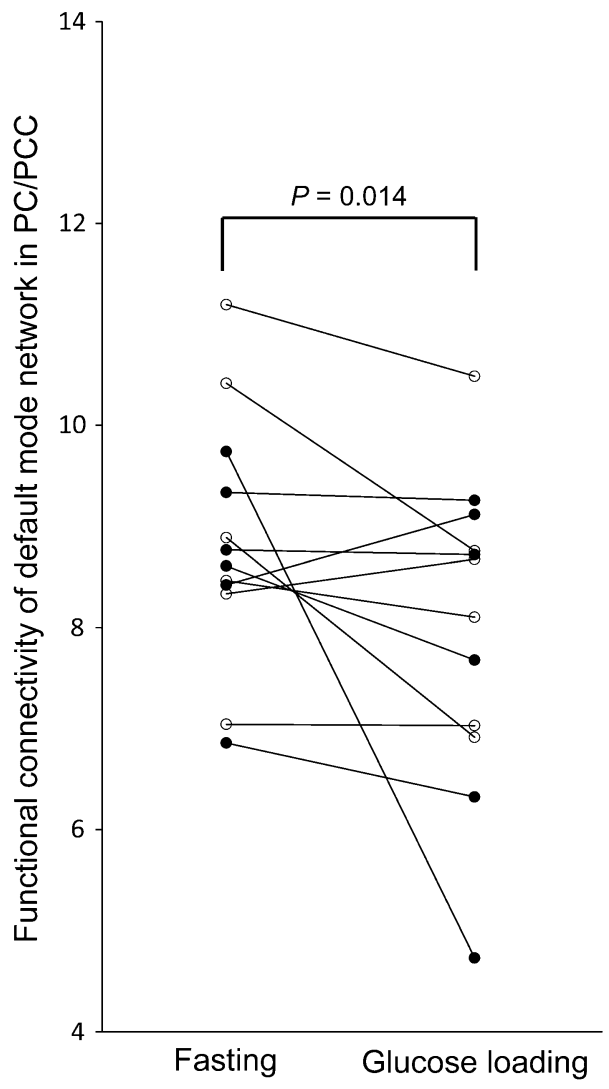

Fig. 4 Differences in the functional connectivity of the DMN in the PC/PCC. The $y$-axis represents the mean $Z$ values in the PC/PCC shown in Fig. 3, which was used for the index of the magnitude of the functional connectivity of the DMN in the PC/PCC. The functional connectivity was significantly lower in the glucose loading condition compared with the fasting condition $(Z=2.197, P=0.014$, one-tailed Wilcoxon signed-rank test). Closed and open circles represent males and females, respectively. DMN default mode network, PC/PCC precuneus/posterior cingulate cortex

the DMN is decreased even in healthy individuals without T2DM and insulin resistance. Zhang and colleagues recently evaluated the acute effects of insulin administration on the resting-state brain network in patients with T2DM, and showed that insulin administration increased the functional connectivity between the hippocampus and the DMN [38]. Because insulin administration induces a reduction in plasma glucose levels, their findings could be restated as showing that a decrease in plasma glucose levels increases the functional connectivity of the DMN. Thus, their findings from patients with T2DM are consistent with our results. However, because the number of participants was relatively small in the present study, our results require further validation in a future study with a large number of participants.

One of the concerns of this study is a lack of understanding as to what the reduction in the functional connectivity of the DMN by glucose loading physiologically reflects. There are several studies using ${ }^{18} \mathrm{~F}$-FDG PET, reporting that increased plasma glucose levels decrease glucose metabolism (i.e., neuronal activity), especially in the PC/PCC $[24,28]$. In a dynamic ${ }^{18} \mathrm{~F}$-FDG PET study with arterial blood sampling, which directly measured net glucose metabolism, glucose loading decreased glucose metabolism in DMN-related regions, especially in the PC/PCC, in young, healthy individuals free of T2DM and insulin resistance [28]. Considering these findings, reduced functional connectivity of the DMN by glucose loading is possibly responsible for reduced neuronal activity in DMN-related regions, especially in the PC/PCC.

Interestingly, plasma glucose levels in the prediabetes range of $100-126 \mathrm{mg} / \mathrm{dL}$ [39] are associated with cognitive decline, as measured using a battery of neuropsychological tests [40-42]. There is an inverse association between plasma glucose levels and Mini Mental State Examination scores in individuals at high risk for cardiovascular disease [43]. In a sample of non-T2DM elderly subjects, individuals with higher plasma glucose levels tended to have lower Mini Mental State Examination scores [40]. A longitudinal study with a median followup of 6.8 years showed that higher glucose levels might be related to an increased risk for dementia, even among individuals without T2DM [44]. Although it remains unclear as to why mildly increased plasma glucose levels induce cognitive decline, the phenomenon may be speculated as follows: increased plasma glucose levels reduce the functional connectivity of the DMN as well as neuronal activity in its components, particularly the $\mathrm{PC} / \mathrm{PCC}$, which is a central core for regulating complex cognition and behavior $[45,46]$. As a result, subclinical cognitive decline may occur even in individuals without T2DM. This speculation may be important to explain the functional link between T2DM and AD, although future studies are needed to elucidate this hypothesis.

In summary, glucose loading can reduce the DMN functional connectivity and PC/PCC neuronal activity in healthy participants. Although the mechanism underlying this phenomenon is unclear, cholinergic and glutamatergic neurotransmitter systems may play an important role in modulating the functional connectivity of the DMN and neuronal activity in the PC/PCC. This is because both the DMN and PC/PCC are anatomically crucial in regulating complex cognition and behavior [4-6, 45, 46], and cholinergic and glutamatergic systems are associated with cognitive function [47]. Moreover, cholinergic enhancement is reported to increase neuronal activity in the PC/PCC [48]. Hence, glucose loading may modulate these neurotransmitter systems, possibly reducing the functional connectivity of the DMN and 
neuronal activity in the PC/PCC. However, further investigation is needed to elucidate this speculation.

\section{Conclusions}

The present study showed that glucose loading reduces the functional connectivity of the DMN in the PC/PCC in young, healthy participants free of T2DM and insulin resistance. Taken together with the previous knowledge that glucose loading decreases neuronal activity in the $\mathrm{PC} / \mathrm{PCC}$, the present results suggest that decreased functional connectivity of the DMN is possibly responsible for reduced PC/PCC neuronal activity in healthy individuals with increased plasma glucose levels.

\begin{abstract}
Abbreviations
DMN: default mode network; AD: Alzheimer's disease; T2DM: type 2 diabetes mellitus; PC/PCC: precuneus/posterior cingulate cortex; MPFC: medial prefrontal cortex; LPTC: lateral parietotemporal cortex; ${ }^{18}$ F-FDG: fluorine-18-labeled fluorodeoxyglucose; PET: positron emission tomography; fMRI: functional magnetic resonance imaging; HOMA-IR: homeostasis model assessment of insulin resistance.
\end{abstract}

\section{Author's contributions}

$\mathrm{KI}$ and $\mathrm{KI}$ designed the study. $\mathrm{KI}, \mathrm{KS}, \mathrm{KS}, \mathrm{AMT}$, and $\mathrm{KI}$ obtained the data. $\mathrm{KI}$ carried out the data processing. KI, KS, KS, AMT, and KI interpreted the data. All authors were involved in drafting and revising the manuscript. All authors agreed to be accountable for all aspects of the work in ensuring that questions related to the accuracy or integrity of any part of the work are appropriately investigated and resolved. All authors read and approved the final manuscript.

\section{Author details \\ ${ }^{1}$ Research Team for Neuroimaging, Tokyo Metropolitan Institute of Ger- ontology, 35-2 Sakae-cho, Itabashi-ku, Tokyo 173-0015, Japan. ${ }^{2}$ Depart- ment of Diagnostic Radiology, Tokyo Metropolitan Geriatric Hospital, 35-2 Sakae-cho, Itabashi-ku, Tokyo 173-0015, Japan.}

\section{Acknowledgements}

The authors thank Dr. Dara Ghahremani at the Laboratory of Molecular Neuroimaging, UCLA for the advice and support on analyzing the resting-state fMRI data, and the people of Research Team for Neuroimaging at the Tokyo Metropolitan Institute of Gerontology and Department of Diagnostic Radiology at the Tokyo Metropolitan Geriatric Hospital for the technical assistance.

\section{Competing interests}

The authors declare that they have no competing interests.

\section{Availability of data and materials}

Ethical restrictions make data unsuitable for public deposition. Requests for data access will be sent to the Ethics Committee of Tokyo Metropolitan Institute of Gerontology. Please contact Kenji Ishibashi (email: ishibashi@pet. tmig.or.jp) who will lead the authorization process to make the data available upon request.

\section{Consent for publication}

Not applicable.

\section{Ethics approval and consent to participate}

The study was approved by the Ethics Committee of the Tokyo Metropolitan Institute of Gerontology (H28-2). After a detailed explanation of the study, each participant provided written informed consent.

\section{Funding}

This work was supported by Translational Research Grants 2016 of Tokyo

Metropolitan Institute of Gerontology (to Kenji Ishibashi).

\section{Publisher's Note}

Springer Nature remains neutral with regard to jurisdictional claims in published maps and institutional affiliations.

Received: 11 December 2017 Accepted: 24 May 2018

Published online: 31 May 2018

\section{References}

1. Anticevic A, Cole MW, Murray JD, Corlett PR, Wang XJ, Krystal JH. The role of default network deactivation in cognition and disease. Trends Cogn Sci. 2012;16(12):584-92.

2. Shulman GL, Corbetta M, Fiez JA, Buckner RL, Miezin FM, Raichle ME, Petersen SE. Searching for activations that generalize over tasks. Hum Brain Mapp. 1997;5(4):317-22.

3. Raichle ME. The brain's default mode network. Annu Rev Neurosci. 2015;38:433-47.

4. Fransson P, Marrelec $G$. The precuneus/posterior cingulate cortex plays a pivotal role in the default mode network: evidence from a partial correlation network analysis. Neurolmage. 2008;42(3):1178-84.

5. Utevsky AV, Smith DV, Huettel SA. Precuneus is a functional core of the default-mode network. J Neurosci. 2014;34(3):932-40.

6. Raichle ME, MacLeod AM, Snyder AZ, Powers WJ, Gusnard DA, Shulman GL. A default mode of brain function. Proc Natl Acad Sci USA. 2001:98(2):676-82.

7. Sperling RA, Laviolette PS, O'Keefe K, O'Brien J, Rentz DM, Pihlajamaki M, Marshall G, Hyman BT, Selkoe DJ, Hedden T, et al. Amyloid deposition is associated with impaired default network function in older persons without dementia. Neuron. 2009;63(2):178-88.

8. Zhu DC, Majumdar S, Korolev IO, Berger KL, Bozoki AC. Alzheimer's disease and amnestic mild cognitive impairment weaken connections within the default-mode network: a multi-modal imaging study. J Alzheimer's Dis. 2013;34(4):969-84.

9. Wang L, Brier MR, Snyder AZ, Thomas JB, Fagan AM, Xiong C, Benzinger TL, Holtzman DM, Morris JC, Ances BM. Cerebrospinal fluid Abeta42, phosphorylated Tau181, and resting-state functional connectivity. JAMA Neurol. 2013;70(10):1242-8.

10. Sheline $\mathrm{Yl}$, Raichle ME. Resting state functional connectivity in preclinical Alzheimer's disease. Biol Psychiatry. 2013;74(5):340-7.

11. Musen G, Jacobson AM, Bolo NR, Simonson DC, Shenton ME, McCartney RL, Flores VL, Hoogenboom WS. Resting-state brain functional connectivity is altered in type 2 diabetes. Diabetes. 2012;61 (9):2375-9.

12. Zhou H, Lu W, Shi Y, Bai F, Chang J, Yuan Y, Teng G, Zhang Z. Impairments in cognition and resting-state connectivity of the hippocampus in elderly subjects with type 2 diabetes. Neurosci Lett. 2010;473(1):5-10.

13. Chen YC, Jiao Y, Cui Y, Shang SA, Ding J, Feng Y, Song W, Ju SH, Teng GJ. Aberrant brain functional connectivity related to insulin resistance in type 2 diabetes: a resting-state fMRI study. Diabetes Care. 2014;37(6):1689-96.

14. Ohara T, Doi Y, Ninomiya T, Hirakawa Y, Hata J, Iwaki T, Kanba S, Kiyohara Y. Glucose tolerance status and risk of dementia in the community: the Hisayama study. Neurology. 2011;77(12):1126-34.

15. Rosazza C, Minati L. Resting-state brain networks: literature review and clinical applications. Neurol Sci. 2011;32(5):773-85.

16. Heeger DJ, Ress D. What does fMRI tell us about neuronal activity? Nat Rev Neurosci. 2002;3(2):142-51.

17. Aiello M, Salvatore E, Cachia A, Pappata S, Cavaliere C, Prinster A, Nicolai E, Salvatore M, Baron JC, Quarantelli M. Relationship between simultaneously acquired resting-state regional cerebral glucose metabolism and functional MRI: a PET/MR hybrid scanner study. Neurolmage. 2015:113:111-21

18. Friedland RP, Budinger TF, Ganz E, Yano Y, Mathis CA, Koss B, Ober BA, Huesman RH, Derenzo SE. Regional cerebral metabolic alterations in dementia of the Alzheimer type: positron emission tomography with [18F]fluorodeoxyglucose. J Comput Assist Tomogr. 1983;7(4):590-8.

19. Langbaum JB, Chen K, Lee W, Reschke C, Bandy D, Fleisher AS, Alexander GE, Foster NL, Weiner MW, Koeppe RA, et al. Categorical and correlational analyses of baseline fluorodeoxyglucose positron emission tomography images from the Alzheimer's Disease Neuroimaging Initiative (ADNI). Neurolmage. 2009;45(4):1107-16. 
20. Phelps ME, Huang SC, Hoffman EJ, Selin C, Sokoloff L, Kuhl DE. Tomographic measurement of local cerebral glucose metabolic rate in humans with (F-18)2-fluoro-2-deoxy-D-glucose: validation of method. Ann Neurol. 1979;6(5):371-88.

21. Ishibashi K, Kawasaki K, Ishiwata K, Ishii K. Reduced uptake of ${ }^{18} \mathrm{~F}-\mathrm{FDG}$ and ${ }^{15} \mathrm{O}-\mathrm{H}_{2} \mathrm{O}$ in Alzheimer's disease-related regions after glucose loading. J Cereb Blood Flow Metab. 2015;35(8):1380-5.

22. Kawasaki K, Ishii K, Saito Y, Oda K, Kimura Y, Ishiwata K. Influence of mild hyperglycemia on cerebral FDG distribution patterns calculated by statistical parametric mapping. Ann Nucl Med. 2008;22(3):191-200.

23. Burns CM, Chen K, Kaszniak AW, Lee W, Alexander GE, Bandy D, Fleisher AS, Caselli RJ, Reiman EM. Higher serum glucose levels are associated with cerebral hypometabolism in Alzheimer regions. Neurology. 2013;80(17):1557-64.

24. Ishibashi K, Onishi A, Fujiwara Y, Ishiwata K, Ishii K. Effects of glucose, insulin, and insulin resistance on cerebral ${ }^{18} \mathrm{~F}-\mathrm{FDG}$ distribution in cognitively normal older subjects. PLoS ONE. 2017;12(7):e0181400.

25. Ishibashi K, Onishi A, Fujiwara Y, Ishiwata K, Ishii K. Relationship between Alzheimer disease-like pattern of ${ }^{18} \mathrm{~F}-\mathrm{FDG}$ and fasting plasma glucose levels in cognitively normal volunteers. J Nucl Med. 2015;56(2):229-33.

26. Baker LD, Cross DJ, Minoshima S, Belongia D, Watson GS, Craft S. Insulin resistance and Alzheimer-like reductions in regional cerebral glucose metabolism for cognitively normal adults with prediabetes or early type 2 diabetes. Arch Neurol. 2011;68(1):51-7.

27. Ishibashi K, Onishi A, Fujiwara Y, Ishiwata K, Ishii K. Plasma glucose levels affect cerebral ${ }^{18} \mathrm{~F}$-FDG distribution in cognitively normal subjects with diabetes. Clin Nucl Med. 2016;41(6):e274-80.

28. Ishibashi K, Wagatsuma K, Ishiwata K, Ishii K. Alteration of the regional cerebral glucose metabolism in healthy subjects by glucose loading. Hum Brain Mapp. 2016;37(8):2823-32.

29. Jenkinson M, Beckmann CF, Behrens TE, Woolrich MW, Smith SM. FSL. Neurolmage. 2012;62(2):782-90.

30. Smith SM, Jenkinson M, Woolrich MW, Beckmann CF, Behrens TE, Johansen-Berg H, Bannister PR, De Luca M, Drobnjak I, Flitney DE, et al. Advances in functional and structural MR image analysis and implementation as FSL. Neurolmage. 2004;23(Suppl 1):S208-19.

31. Woolrich MW, Jbabdi S, Patenaude B, Chappell M, Makni S, Behrens T, Beckmann C, Jenkinson M, Smith SM. Bayesian analysis of neuroimaging data in FSL. Neurolmage. 2009;45(1 Suppl):S173-86.

32. Lv XF, Qiu YW, Tian JZ, Xie CM, Han LJ, Su HH, Liu ZY, Peng JP, Lin CL, Wu $\mathrm{MS}$, et al. Abnormal regional homogeneity of resting-state brain activity in patients with HBV-related cirrhosis without overt hepatic encephalopathy. Liver Int. 2013;33(3):375-83.

33. Beckmann CF, DeLuca M, Devlin JT, Smith SM. Investigations into restingstate connectivity using independent component analysis. Philos Trans R Soc Lond B Biol Sci. 2005;360(1457):1001-13.

34. Tuovinen T, Rytty R, Moilanen V, Abou Elseoud A, Veijola J, Remes AM, Kiviniemi VJ. The effect of gray matter ICA and coefficient of variation mapping of BOLD data on the detection of functional connectivity changes in Alzheimer's disease and bvFTD. Front Hum Neurosci. 2016;10:680.

35. Power JD, Barnes KA, Snyder AZ, Schlaggar BL, Petersen SE. Spurious but systematic correlations in functional connectivity MRI networks arise from subject motion. Neurolmage. 2012;59(3):2142-54.

36. Kohno M, Okita K, Morales AM, Robertson CL, Dean AC, Ghahremani DG, Sabb FW, Rawson RA, Mandelkern MA, Bilder RM, et al. Midbrain functional connectivity and ventral striatal dopamine D2-type receptors: link to impulsivity in methamphetamine users. Mol Psychiatry. 2016;21(11):1554-60.

37. Keskin M, Kurtoglu S, Kendirci M, Atabek ME, Yazici C. Homeostasis model assessment is more reliable than the fasting glucose/insulin ratio and quantitative insulin sensitivity check index for assessing insulin resistance among obese children and adolescents. Pediatrics. 2005;115(4):e500-3.

38. Zhang H, Hao Y, Manor B, Novak P, Milberg W, Zhang J, Fang J, Novak V. Intranasal insulin enhanced resting-state functional connectivity of hippocampal regions in type 2 diabetes. Diabetes. 2015;64(3):1025-34.

39. American Diabetes A. 2. Classification and diagnosis of diabetes. Diabetes Care. 2017:40(Suppl 1):S11-24.

40. Di Bonito P, Di Fraia L, Di Gennaro L, Vitale A, Lapenta M, Scala A, lardino MR, Cusati B, Attino L, Capaldo B. Impact of impaired fasting glucose and other metabolic factors on cognitive function in elderly people. Nutr Metab Cardiovasc Dis. 2007;17(3):203-8.

41. Yaffe K, Blackwell T, Kanaya AM, Davidowitz N, Barrett-Connor E, Krueger K. Diabetes, impaired fasting glucose, and development of cognitive impairment in older women. Neurology. 2004;63(4):658-63.

42. Cukierman-Yaffe T, Gerstein HC, Anderson C, Zhao F, Sleight P, Hilbrich L, Jackson SH, Yusuf S, Teo K, Investigators OT. Glucose intolerance and diabetes as risk factors for cognitive impairment in people at high cardiovascular risk: results from the ONTARGET/TRANSCEND research programme. Diabetes Res Clin Pract. 2009;83(3):387-93.

43. Cukierman-Yaffe T. Diabetes, dysglycemia and cognitive dysfunction. Diabetes Metab Res Rev. 2014;30(5):341-5.

44. Crane PK, Walker R, Hubbard RA, Li G, Nathan DM, Zheng H, Haneuse S, Craft S, Montine TJ, Kahn SE, et al. Glucose levels and risk of dementia. N Engl J Med. 2013;369(6):540-8.

45. Cavanna AE, Trimble MR. The precuneus: a review of its functional anatomy and behavioural correlates. Brain. 2006;129(Pt 3):564-83.

46. Leech R, Sharp DJ. The role of the posterior cingulate cortex in cognition and disease. Brain. 2014;137(Pt 1):12-32.

47. Francis PT, Parsons CG, Jones RW. Rationale for combining glutamatergic and cholinergic approaches in the symptomatic treatment of Alzheimer's disease. Expert Rev Neurother. 2012;12(11):1351-65.

48. lizuka T, Kameyama M. Cholinergic enhancement increases regional cerebral blood flow to the posterior cingulate cortex in mild Alzheimer's disease. Geriatr Gerontol Int. 2017;17(6):951-8.

\footnotetext{
Ready to submit your research? Choose BMC and benefit from:

- fast, convenient online submission

- thorough peer review by experienced researchers in your field

- rapid publication on acceptance

- support for research data, including large and complex data types

- gold Open Access which fosters wider collaboration and increased citations

- maximum visibility for your research: over $100 \mathrm{M}$ website views per year
}

At BMC, research is always in progress.

Learn more biomedcentral.com/submissions 